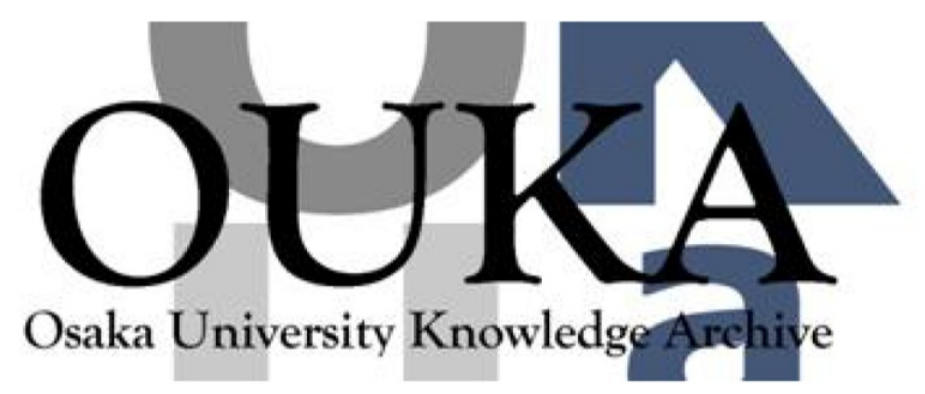

\begin{tabular}{|c|l|}
\hline Title & $\begin{array}{l}\text { Hugoniot measurement of diamond under laser } \\
\text { shock compression up to } 2 \text { Tpa }\end{array}$ \\
\hline Author(s) & Nagao, H.; Nakamura, K. G.; Kondo, K. et al. \\
\hline Citation & Physics of Plasmas. 13(5) p.052705 \\
\hline Issue Date & $2006-05$ \\
\hline oaire:version VoR \\
\hline URL & https://hdl. handle. net/11094/3360 \\
\hline rights & \\
\hline Note & \\
\hline
\end{tabular}

Osaka University Knowledge Archive : OUKA

https://ir. Library. osaka-u. ac. jp/

Osaka University 


\title{
Hugoniot measurement of diamond under laser shock compression up to $2 \mathrm{TPa}$
}

\author{
H. Nagao, K. G. Nakamura, ${ }^{\text {a) }}$ and K. Kondo \\ Materials and Structures Laboratory, Tokyo Institute of Technology, Box R3-10, 4259 Nagatsuta, \\ Midori, Yokohama, Kanagawa 226-8503, Japan
}

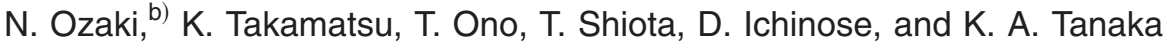

Graduate School of Engineering and Institute of Laser Engineering, Osaka University, 2-6 Yamada-oka, Suita, Osaka 565-0871, Japan

K. Wakabayashi, K. Okada, and M. Yoshida

Research Center for Explosion Safety, National Institute of Advanced Industrial Science and Technology, Central No.5, 1-1-1 Higashi, Tsukuba, Ibaraki 305-8565, Japan
\end{abstract}

M. Nakai, K. Nagai, K. Shigemori, T. Sakaiya, and K. Otani

Institute of Laser Engineering, Osaka University, 2-6 Yamada-oka, Suita, Osaka 565-0871, Japan

(Received 7 November 2005; accepted 25 April 2006; published online 26 May 2006)

\begin{abstract}
Hugoniot data of diamond was obtained using laser-driven shock waves in the terapascal range of 0.5-2 TPa. Strong shock waves were generated by direct irradiation of a $2.5 \mathrm{~ns}$ laser pulse on an $\mathrm{Al}$ driver plate. The shock wave velocities in diamond and Al were determined from optical measurements. Particle velocities and pressures were obtained using an impedance matching method and known Al Hugoniot. The obtained Hugoniot data of diamond does not show a marked difference from the extrapolations of the Pavlovskii Hugoniot data in the TPa range within experimental errors. @ 2006 American Institute of Physics. [DOI: 10.1063/1.2205194]
\end{abstract}

\section{INTRODUCTION}

The study of the equation of state (EOS) of materials under extremely high-pressure conditions is of great interest in several fields of modern physics. ${ }^{1}$ For example, in inertial fusion energy (IFE) research, ${ }^{2-4}$ compression efficiency and shock structure in fusion capsules critically depend on the EOS. ${ }^{2,3}$ Such hydrodynamic and thermodynamic conditions are evaluated by numerical codes generally employing wellknown EOS models. ${ }^{5,6}$ EOS at high pressures is obtained on the basis of the shock Hugoniot data. In order to design and address experiments such as hydrodynamic instabilities ${ }^{7,8}$ and fast ignition, ${ }^{9}$ accurate EOS and Hugoniot data of materials are required.

The EOS of diamond at ultrahigh pressures is attracting much attention not only in materials sciences but also in astrophysics. Diamond is a stable phase of carbon at high pressures of approximately $300 \mathrm{GPa}$ and is one of the most important materials because of its high hardness, low compressibility, and high resistivity. Many theoretical calculations were conducted on the ultrahigh-pressure phase of carbon and suggested several new phases ${ }^{10,11}$ such as $\mathrm{BC} 8{ }^{12}$ liquid carbon, ${ }^{13,14}$ and metallic carbon ${ }^{15}$ at pressures above $1 \mathrm{TPa}$. Information about the ultrahigh-pressure phase of carbon is also important in astrophysics, because carbon is a major element of giant planets such as Uranus and Neptune ${ }^{16}$ and pressures inside giant planets are very high (e.g., $600 \mathrm{GPa}$ at the core of Neptune).

\footnotetext{
${ }^{a)}$ Author to whom correspondence should be addressed. Electronic mail: nakamura@msl.titech.ac.jp

${ }^{b)}$ Present address: Laboratorie pour l'Utilisation des Lasers Intenses, Ecole Polytechnique, 91128 Palaiseau Cedex, France.
}

However, the phase of carbon in the TPa regime is still an open question, ${ }^{10-24}$ because experimentally obtained Hugoniot measurements of diamond are few and limited to below $600 \mathrm{GPa}$. Pavlovskii ${ }^{25}$ measured four Hugoniot data points for single-crystalline diamond up to $590 \mathrm{GPa}$ using an underground nuclear explosion, and reported that shock velocity $\left(U_{s}^{\text {Dia }}\right)$ and particle velocity $\left(u_{p}^{\text {Dia }}\right)$ satisfy a linear relationship $U_{s}^{\mathrm{Dia}}=12.16+1.00 u_{p}^{\mathrm{Dia}}$. Kondo and Ahrens ${ }^{26}$ measured two Hugoniot data points at 191 and $217 \mathrm{GPa}$ using an impact gun. Recently, Bradley et al. ${ }^{24}$ have measured the reflectivity of shock-compressed diamond in a wide continuous pressure range by assuming a decaying shock front as a model of the Hugoniot. They suggested that diamond changes to a conducting fluid at $1 \mathrm{TPa}$, however, they used a theoretical EOS model ${ }^{13}$ to determine shock pressure. Wang et $a .^{27}$ have reported carbon phase diagram from $a b$ initio molecular dynamics calculation. Their calculated melting curve is in excellent agreement with the experimental estimate of the graphite-diamond-liquid triple point and is consistent with shock wave experiments.

The EOS data and Hugoniot data of diamond in the TPa regime are desired to be determined experimentally. In this study, we obtained the Hugoniot data of single-crystalline diamond along the (110) plane at pressures of 0.5-2 TPa using laser-driven shock compression.

\section{EXPERIMENT}

Shock compression experiments were performed using the GEKKO/HIPER laser facility in the Institute of Laser Engineering (ILE) ${ }^{28}$ which provides uniform laser irradiation at a wavelength of $351 \mathrm{~nm}$ and a high intensity. The 


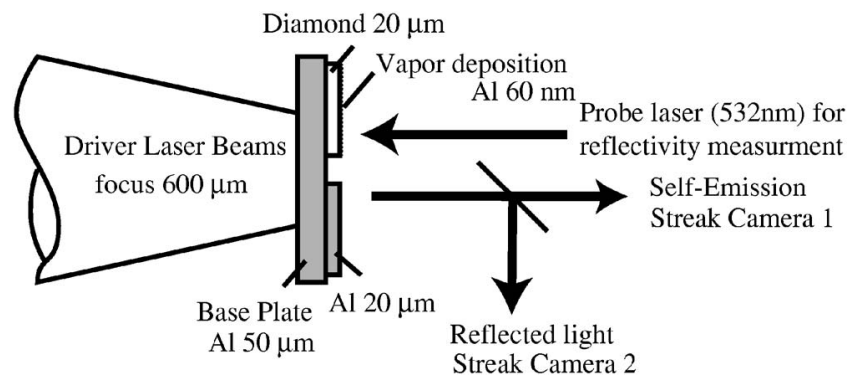

FIG. 1. Configuration of laser irradiation setup and target assembly for EOS measurements and diagnostic system setup.

laser beams are smoothed by the spectral dispersion (SSD) technique. ${ }^{29}$ Kinoform phase plates (KPPs) (Ref. 30) are installed for all beams to obtain a uniform irradiation pattern. The pulse width is $2.5 \mathrm{~ns}$ at full width at half maximum (FWHM) with rise and fall times of 100 ps. The laser beam was focused on the sample at a spot with a $600 \mu \mathrm{m}$ diameter. The focused spot was monitored using an x-ray pinhole camera. Figure 1 shows the target assembly and experimental setup. $^{31}$

The target consists of a $50 \mu \mathrm{m}$ thick Al base plate, a $20 \mu \mathrm{m}$ thick Al sample, and a $20 \mu \mathrm{m}$ thick diamond sample coated with a $50 \mathrm{~nm}$ thick Al layer. The thickness of the samples were measured by a laser scanning microscope, which is a laser microscope with a scanning type laser displacement sensor system and has a resolution of $0.01 \mu \mathrm{m}$. Thicknesses of the samples were in a range between $18.56 \mu \mathrm{m}$ and $22.00 \mu \mathrm{m}$. Uncertainty of the measured thickness of each sample was lower than $1.2 \%$, which also includes surface roughness. This contribution to uncertainties in shock velocities is much smaller than that of shock breakout time. The diamond sample is natural type 2 a diamond and the surface is the (110) plane. The base plate and the samples were glued by the single-molecular-membrane glue technique $^{32}$ using alkylsilanehalide. The adhesion layer is very thin $(<100 \mathrm{~nm})$ and sufficient to neglect its thickness to measure the shock propagation time in the samples. The shock wave velocities of diamond and Al were obtained from optical measurements and pressure and particle velocity were obtained using an impedance matching method. Al was chosen as a reference material because the EOS of $\mathrm{Al}$ is well determined at ultrahigh pressures of up to $1.5 \mathrm{TPa}$. The densities of diamond (obtained from Element Six Corp.) and Al (purity of $99.3 \%$, obtained from TOYO Aluminum K.K.) are $3.51 \mathrm{~g} / \mathrm{cm}^{3}$ and $2.71 \mathrm{~g} / \mathrm{cm}^{3}$, respectively. The rear side of diamond was deposited with a $60 \mathrm{~nm}$ thick Al layer.

In the experiments, two diagnostic systems were used to measure a target rear-side event at the same time. One system was a measurement of the reflection of a probe laser from the target rear side. An injection-seeded Q-switched Nd:YAG (yttrium aluminum garnet) laser was used as the probe light. The maximum energy was $0.7 \mathrm{~J}$ at a wavelength of $532 \mathrm{~nm}$. The original pulse duration was approximately 8 ns (FWHM) with a Gaussian shape. The probe laser was focused into one end of an optical fiber using a lens and was passed through the fiber to near the vacuum target chamber. The other end of the fiber was coupled to the target with a

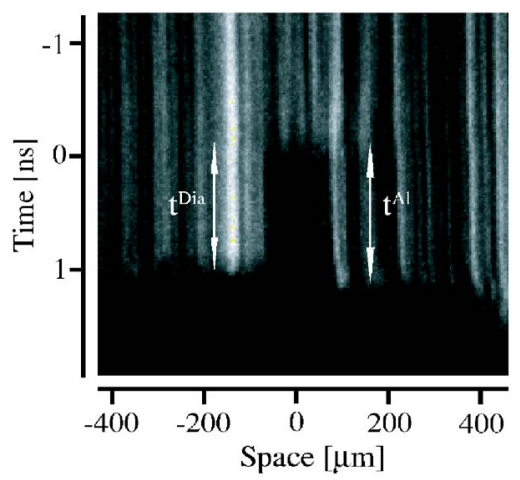

FIG. 2. Streak image by the reflectivity measurement. $t^{\mathrm{Al}}$ and $t^{\mathrm{Dia}}$ indicate the transit times of the shocks traveling through each step.

fiber collimator and a lens, thus the probe light was collimated in front of a focal lens of $F / 3$ in the backlighter beamline of the HIPER system. The YAG probe illuminated the target rear surface using the focal lens of the backlighter beam. Specular reflection of the probe was collected by the same optics utilized in the self-emission measurement. The light was collected by an $F / 2.8$ lens and reflected by a laser mirror at a probe wavelength of $532 \mathrm{~nm}$ and was focused on the slit of the other streak camera system (Hamamatsu Photonics S-20). Note that a notch filter ( $<10 \mathrm{~nm}$ bandwidth) for the $532 \mathrm{~nm}$ wavelength of YAG was installed to prevent self-emission measurement from the probe light signal. The target rear image was rotated vertically by a dove prism to arrange the step edge of the target on the streak slit. We used a value $(0.22 \%)$ of the linearity of sweep speed of the streak camera. Time resolution of the streak camera is $4.99 \mathrm{ps} / \mathrm{pixel}$. The breakout time was determined at the center area $(30$ pixel points $=30 \mu \mathrm{m})$ at each step and the base plate. Average values and errors of shock breakout times were calculated. Error of shock breakout times obtained by this method also includes uncertainties of shock-wave steadiness and curvature. The uncertainties of the breakout time is less than $9 \%$, which is much larger than that of step heights and other uncertainties. Although we have considered other sources of errors, the final error of shock speed is nearly equal to the uncertainties of the breakout time. The other system was a measurement of self-emission from shock breakout at the rear surface using a visible streak camera (Hamamatsu Photonics S-20). The self-emission signals were collected and were image-relayed on the slit of the streak camera. In this optical path, notch filters were installed for $527 \mathrm{~nm}$ and $351 \mathrm{~nm}$ wavelengths to avoid GEKKO XII drive laser beams. Although the two measurement systems could be used at the same time in principle, the simultaneous measurements was not performed in the experiments, because light intensity of self-emission is too weak to detect by the streak camera at lower pressure range $(<1000 \mathrm{GPa})$.

\section{RESULT AND DISCUSSION}

Figure 2 shows a typical streak image of the reflected probe light from the rear side of the target, which was driven by laser irradiation at a laser intensity of $1.4 \times 10^{13} \mathrm{~W} / \mathrm{cm}^{2}$. The reflectivities of the aluminum surface and aluminum- 


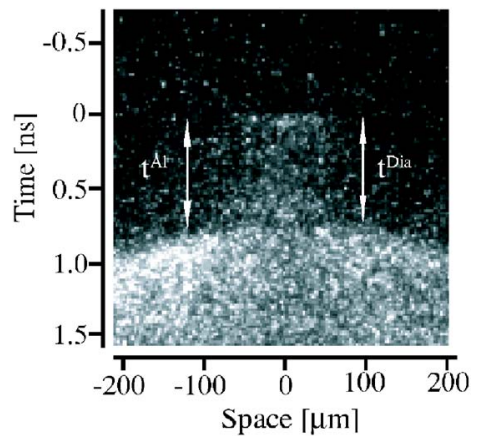

FIG. 3. Streak image obtained by self-emission measurement. $t^{\mathrm{Al}}$ and $t^{\mathrm{Dia}}$ indicate the transit times of the shocks traveling through each step.

coated diamond surface decrease rapidly upon shock emergence. No significant decrease in reflectivity was detected before the shock arrival at the rear surface. We find the reflectivity decreases rapidly at shock emergence by reflection measurement. No significant decrease of reflectivity was detected before the shock arrival at the rear surface. The decrement before the shock breakout can be estimated as not more than $5 \%{ }^{31}$ This is consistent with about $<0.08 \mathrm{eV}$. $^{40}$ The shock propagation times in diamond and aluminum were determined on the basis of the differences between the vanish time of the reflection from the rear side of the base plate and those at the diamond and aluminum steps, respectively. The shock velocity was obtained by dividing the thickness of the step with arrival time. The shock velocities in diamond $\left(U_{s}^{\mathrm{Dia}}\right)$ and $\mathrm{Al}\left(U_{s}^{\mathrm{Al}}\right)$ at a laser intensity of 1.4 $\times 10^{13} \mathrm{~W} / \mathrm{cm}^{2}$ were obtained at $19.9( \pm 0.9) \mathrm{km} / \mathrm{s}$ and 16.8 $( \pm 1.0) \mathrm{km} / \mathrm{s}$, respectively.

Figure 3 shows a streak image of self-emission from the sample at a laser intensity of $1.3 \times 10^{14} \mathrm{~W} / \mathrm{cm}^{2}$. The streak image shows a spatial uniform shock wave at the central area of the target. The arrival of the shock wave at the rear surfaces is set to time zero for the emission. The shock propagation times in diamond and $\mathrm{Al}$ were determined on the basis of differences in the emission time from the rear side of the base plate and those at the diamond and $\mathrm{Al}$ steps, respectively. The shock velocity was obtained by dividing the thickness of the step with the arrival time. $U_{s}^{\mathrm{Dia}}$ and $U_{s}^{\mathrm{Al}}$ at a laser intensity of $1.4 \times 10^{14} \mathrm{~W} / \mathrm{cm}^{2}$ were obtained at 32.7 $( \pm 1.7) \mathrm{km} / \mathrm{s}$ and $31.2( \pm 2.3) \mathrm{km} / \mathrm{s}$, respectively.

Using the impedance-matching method, the pressures and particle velocities of diamond were obtained with the shock wave velocity of aluminum and the aluminum Hugoniot. ${ }^{33,34}$ The aluminum Hugoniot has been experimentally and theoretically investigated over a wide range of pressures. We used a simple linear relationship between shock wave velocity and particle velocity as suggested in Ref. 34, which is in good agreement with experimental Hugoniot data in the TPa region. The particle velocity and pressure state of aluminum corresponding to the measured shock velocity were determined using the aluminum Hugoniot. We used the $\mathrm{Al}$ EOS $\left[U_{s}^{\mathrm{Al}}=5.685( \pm 0.160)+1.275( \pm 0.026) u_{p}^{\mathrm{Al}}\right]$, which was obtained based on the experimental $\left(U_{s}\right)$ values in a range between 10 and $28 \mathrm{~km} / \mathrm{s}$. Therefore, the extracted diamond EOS is based on extrapolation of Al EOS. When the shock wave propagates through the interface between aluminum and diamond, a reflected shock travels in the primary shocked aluminum. The reflected shock condition is given by the intersection of the reshock curve calculated using the Grüneisen parameter of aluminum, the aluminum Hugoniot, and the Ralyleigh line of diamond. The reflected shock curve of aluminum was calculated on the basis of the following equation $^{35}$

$$
P_{2}=\frac{P_{H}-(\gamma / V)\left[\left(P_{H}-P_{1}\right)\left(V_{0}-V_{2}\right) / 2\right]}{1-(\gamma / V)\left(V_{1}-V_{2}\right) / 2} .
$$

In this equation, subscript 2 refers to the reshock state. Here, $P_{H}$ is the pressure on the original Hugoniot of aluminum at the volume $V_{2}$. The point $P_{1}, V_{1}$ is the centering point for the second shock and lies on the original Hugoniot, which is centered at zero pressure and the volume $V_{0}$. For present applications the Grüneisen $\gamma$ is usually determined from the relationship

$$
\gamma / V=\gamma_{0} / V_{0}
$$

although the assumption is not well-founded at extreme pressures. In the calculation, we used the Grüneisen parameter for aluminum, $\gamma_{0}=2.15,{ }^{36}$ which is based on $\mathrm{Al}(1100)$ which is pure aluminum (purity is over 99.0\%). The purity and density are almost equal to the sample used for the present study.

The obtained Hugoniot data are listed in Table I. In the previously published data, ${ }^{37}$ is possible to contain large errors which is approximately $25 \%$, because of problems of the step height measurements. In this paper, only the latest data have been quoted.

TABLE I. Summary of shock compression of diamond. $U_{s}^{\mathrm{Al}}$ and $U_{s}^{\mathrm{Dia}}$ are the measured shock velocities of Al and diamond, respectively. $u_{p}^{\text {Dia }}, P^{\text {Dia }}$, and $V^{\text {Dia }}$ are the calculated particle velocity and shock pressure of diamond, respectively.

\begin{tabular}{cccccc}
\hline \hline Shot No. & $U_{s}^{\mathrm{Al}}(\mathrm{km} / \mathrm{s})$ & $U_{s}^{\text {Dia }}(\mathrm{km} / \mathrm{s})$ & $u_{p}^{\text {Dia }}(\mathrm{km} / \mathrm{s})$ & $P^{\text {Dia }}(\mathrm{TPa})$ & $V^{\text {Dia }}\left(\mathrm{m}^{3} / \mathrm{Mg}\right)$ \\
\hline 26332 & $26.6( \pm 3.8 \%)$ & $29.0( \pm 4.0 \%)$ & $14.4( \pm 8.8 \%)$ & $1.48( \pm 9.7 \%)$ & $0.134( \pm 6.1 \%)$ \\
26396 & $16.8( \pm 6.1 \%)$ & $19.9( \pm 4.3 \%)$ & $7.35( \pm 14.5 \%)$ & $0.513( \pm 15.5 \%)$ & $0.128( \pm 11.2 \%)$ \\
27300 & $31.2( \pm 7.3 \%)$ & $32.7( \pm 5.2 \%)$ & $18.0( \pm 14.5 \%)$ & $2.07( \pm 16.4 \%)$ & $0.179( \pm 11.0 \%)$ \\
28693 & $25.9( \pm 7.0 \%)$ & $27.2( \pm 5.3 \%)$ & $14.2( \pm 14.5 \%)$ & $1.36( \pm 15.4 \%)$ & $0.136( \pm 11.4 \%)$ \\
28695 & $18.1( \pm 5.5 \%)$ & $21.4( \pm 6.2 \%)$ & $8.24( \pm 12.9 \%)$ & $0.619( \pm 14.3 \%)$ & $0.175( \pm 9.6 \%)$ \\
28697 & $22.5( \pm 4.8 \%)$ & $24.6( \pm 9.3 \%)$ & $11.5( \pm 11.0 \%)$ & $0.996( \pm 14.4 \%)$ & $0.151( \pm 8.4 \%)$ \\
\hline \hline
\end{tabular}




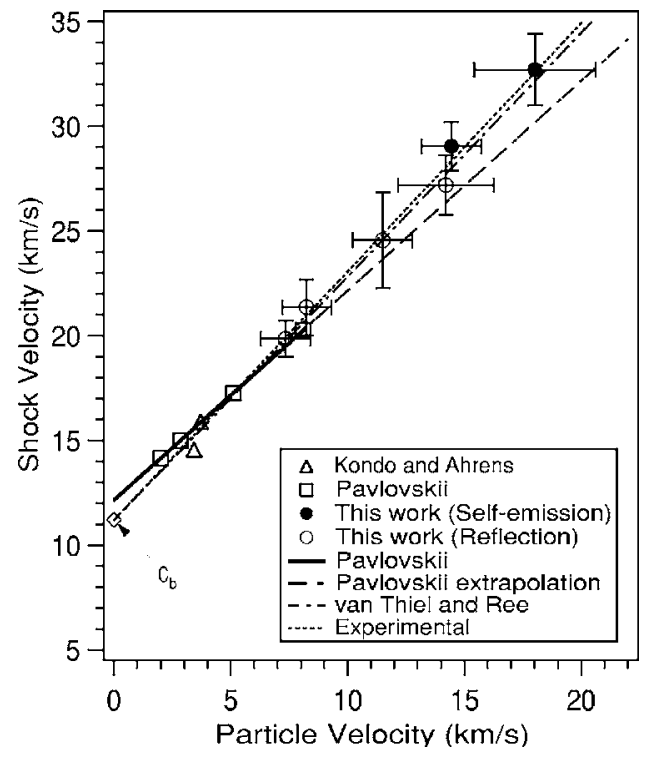

FIG. 4. Shock velocity-particle velocity relationship. Present results: solid circles (self-emission measurement) and open circle (reflected-light measurement) with error bars; Pavlovskii (Ref. 25), open squares; Kondo and Ahrens (Ref. 26), open triangles. Solid line is Pavlovskii Hugoniot (Ref. 25) and the dashed line is the extrapolation curve of the Pavlovskii Hugoniot. Long and short dashed line is calculated using van Thiel and Ree EOS parameters (Ref. 13). Short dashed line is obtained using all experimental Hugoniot. $C_{b}$, bulk sound velocity, is $11.2 \mathrm{~km} / \mathrm{s}$, calculated from Refs. 38 and 39 .

At a laser intensity of $1.4 \times 10^{13} \mathrm{~W} / \mathrm{cm}^{2}$, the generated pressure and particle velocity in diamond were obtained at $513 \mathrm{GPa}$ and $7.35 \mathrm{~km} / \mathrm{s}$, respectively. The obtained shock and particle velocities agree well with those $\left(U_{s}^{\mathrm{Dia}}=12.16\right.$ $\left.+1.00 u_{p}^{\text {Dia }}\right)$ obtained by Pavlovskii ${ }^{25}$ using an underground nuclear explosion at pressures below $590 \mathrm{GPa}$. Figure 4 shows the obtained shock velocity and particle velocity along with the Hugoniot data in the literature. ${ }^{25,26}$ Figure 5 shows the obtained pressure and particle velocity along with the Hugoniot data in the literature. ${ }^{25,26}$ Figure 6 shows a relation between pressure and volume. The obtained Hugoniot data do not show a marked difference between the extrapolation (dashed line in Figs. 4-6) of the Pavlovskii Hugoniot up to $2 \mathrm{TPa}$ and the calculation with van Thiel and Ree (VTR) EOS parameters ${ }^{13}$ (long and short dashed line in Figs. 4-6) within experimental errors. The dependence of $U_{s}^{\mathrm{Dia}}\left(u_{p}^{\mathrm{Dia}}\right)$ obtained for single-crystalline diamond could be approximated by the linear relationship $U_{s}^{\mathrm{Dia}}=11.2( \pm 0.2)$ $+1.2( \pm 0.1) u_{p}^{\text {Dia }}$ for the obtained Hugoniot data, previous experimental data, ${ }^{25,26}$ and the bulk sound velocity. ${ }^{38,39}$ The obtained experimental Hugoniot is close to VTR EOS. According to Bradley's results, ${ }^{24}$ diamond above $1 \mathrm{TPa}$ is a metallic fluid. Although our results include a relatively large amount of errors, the large extension of Hugoniot measurements is important. In the Hugoniot measurement, it is difficult to detect a decrease in volume corresponding to the phase transition. Wang et $a l .{ }^{27}$ have reported the melting line of carbon at ultrahigh pressure $(>600 \mathrm{GPa})$ and estimated negative inclination calculated by $a b$ initio molecular dynamics simulation. Present data suggest that the volume change between diamond and metallic liquid carbon under

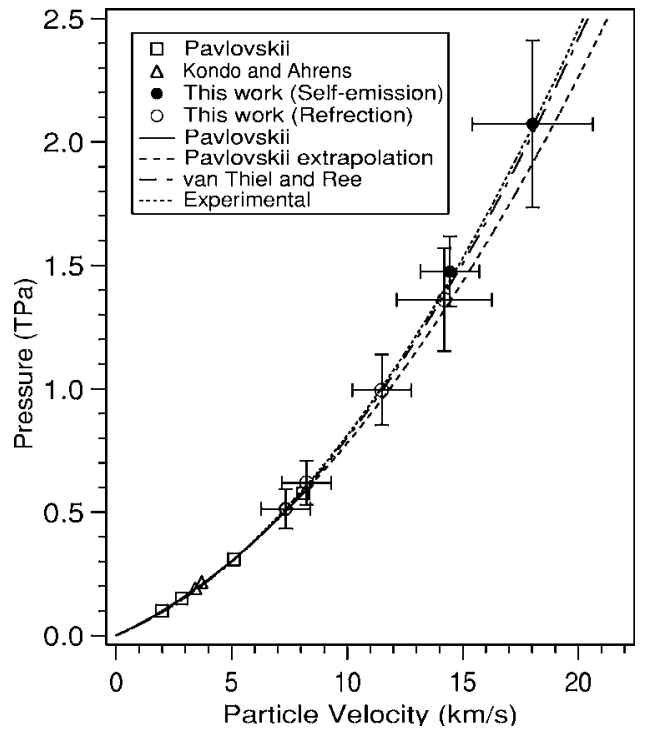

FIG. 5. Diamond Hugoniot pressure-particle velocity relationship. Present results: solid circles (self-emission measurement) and open circles (reflected light measurement) with error bar; Pavlovskii (Ref. 25), open squares; Kondo and Ahrens (Ref. 26), open triangles. Solid line is Pavlovskii Hugoniot (Ref. 25) and the dashed line is the extrapolation curve of Pavlovskii Hugoniot. Long and short dashed line is calculated using van Thiel and Ree EOS parameters (Ref. 13). Short dashed line is obtained using all experimental Hugoniot.

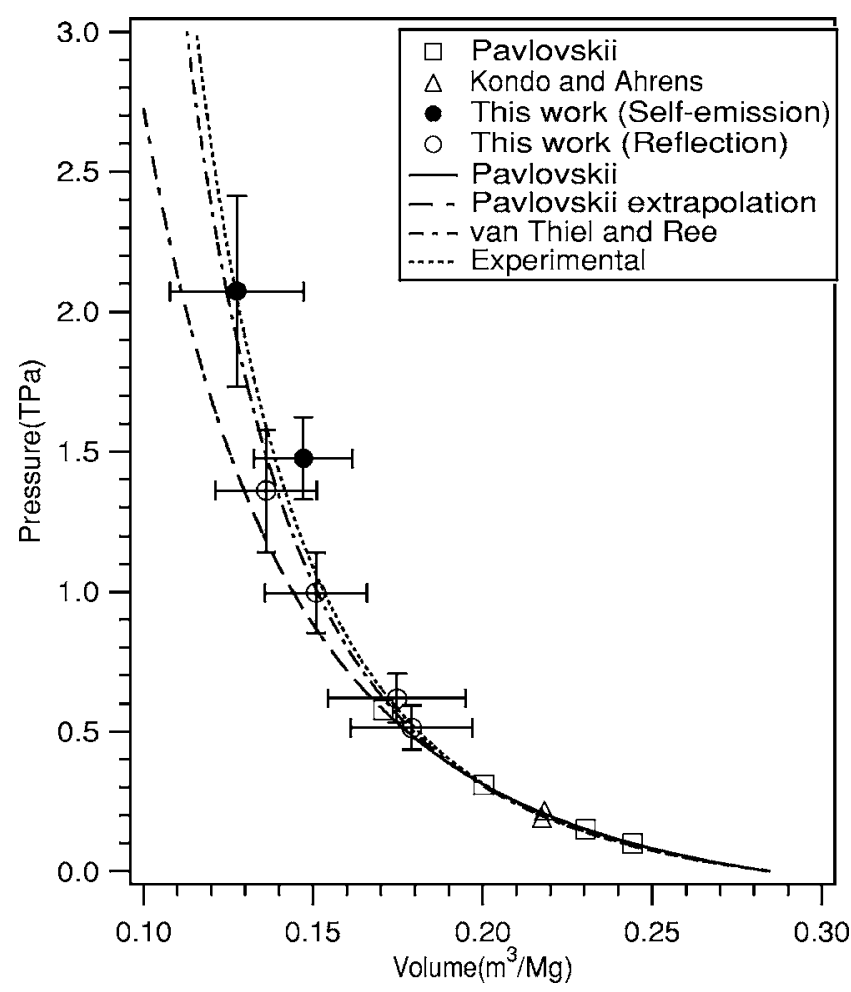

FIG. 6. Diamond Hugoniot pressure-volume velocity relationship. Present results: solid circles (self-emission measurement) and open circles (reflected light measurement) with error bar; Pavlovskii (Ref. 25), open squares; Kondo and Ahrens (Ref. 26), open triangles. Solid line is Pavlovskii Hugoniot (Ref. 25) and the dashed line is the extrapolation curve of Pavlovskii Hugoniot. Long and short dashed line is calculated using van Thiel and Ree EOS parameters (Ref. 13). Short dashed line is obtained using all experimental Hugoniot. 
shock compression is too small to define in this experimental error range.

In the shock wave EOS experiment, a specific general limit existed, that is, we could obtain data only on the Hugoniot curve of the material. This is because the shock wave compresses and heats the material at the same time, so pressure and temperature are no longer two independent variables. Highly shock-compressed diamond in the terapascal region has a high temperature. The shock temperature at $2 \mathrm{TPa}$ is estimated to be $4.4 \times 10^{4} \mathrm{~K}$ using VTR EOS and including the heat consumption of melting. The phase is supposed to be in liquid form at $4.4 \times 10^{4} \mathrm{~K}$ and $2 \mathrm{TPa}$, if we believe the known phase diagram. ${ }^{19}$ However, no significant change in curvature, which corresponds to the phase transition, is observed in the obtained Hugoniot curve up to $2 \mathrm{TPa}$. Despite extremely high pressures, high temperatures, and the possibility of getting across the phase boundary between the solid phase and liquid phase, the present EOS data indicate that the compressibility of diamond in the $\mathrm{TPa}$ region changes little from that in the low-pressure range. Accurate EOS experiment with small errors, electrical measurement, and temperature measurement will be required in further experiments to specify the state of carbon in ultrahigh pressures and temperatures.

\section{ACKNOWLEDGMENTS}

The authors gratefully acknowledge the invaluable support of the GXII technical crews and scientists at ILE with the experiments. In particular, the authors would like to thank K. Suzuki, S. Urushihara, H. Asahara, and N. Morio for operating GXII. The authors would like to thank Y. Igarashi (MSL) for experimental and analytical support.

H. N. is grateful to the JSPS fellowship and the 21st Century COE Program by four materials-related Departments at the Tokyo Institute of Technology for financial support.

${ }^{1}$ W. J. Nellis, M. Ross, and N. C. Holmes, Science 269, 1249 (1995).

${ }^{2}$ S. W. Hanna, S. M. Pollaine, J. D. Lindl, L. J. Suter, R. L. Berger, L. V. Powers, W. E. Alley, P. A. Amendt, J. A. Futterman, W. K. Levedahl, M. D. Rosen, D. P. Rowley, R. A. Sacks, A. I. Shestakov, G. L. Strobel, M. Tabak, S. V. Weber, G. B. Zimmerman, W. J. Krauser, D. C. Wilson, S. V. Coggeshall, D. B. Harris, N. M. Hoffman, and B. H. Wilde, Phys. Plasmas 2, 2480 (1995).

${ }^{3}$ J. D. Lindl, Phys. Plasmas 2, 3933 (1995).

${ }^{4}$ T. R. Dittrich, S. W. Haan, M. M. Marinak, S. M. Pollaine, D. E. Hinkel, D. H. Munro, C. P. Verdon, G. L. Strobel, R. McEachern, R. C. Cook, C. C. Roberts, D. C. Wilson, P. A. Bradley, L. R. Foreman, and W. S. Varnum, Phys. Plasmas 6, 2164 (1999).

${ }^{5}$ R. M. More, K. H. Warren, D. A. Young, and G. B. Zimmerman, Phys. Fluids 31, 3059 (1988).

${ }^{6}$ SESAME, the LANL equation of state database. See National Technical Information Service Document No. DE94011699. Copies may be ordered from the National Technical Information Service, Springfield VA 22161.

${ }^{7}$ R. J. Taylor, Phys. Rev. Lett. 76, 1643 (1996).

${ }^{8}$ H. Azechi, M. Nakai, K. Shigemori, N. Miyanaga, H. Shiraga, H. Nish- imura, M. Honda, R. Ishizaki, J. G. Wouchuk, H. Takabe, K. Nishihara, K. Mima, A. Nishiguchi, and T. Endo, Phys. Plasmas 4, 4079 (1997).

${ }^{9}$ K. A. Tanaka, R. Kodama, K. Mima, Y. Kitagawa, H. Fujita, N. Miyanaga, K. Nagai, T. Norimatsu, T. Sato, Y. Sentoku, K. Shigemori, A. Sunahara, T. Shozaki, M. Tanpo, S. Tohyama, T. Yabuuchi, J. Zheng, T. Yamanaka, P. A. Norreys, R. Evanse, M. Zepf, K. Krushelnic, A. Dangor, R. Stephens, S. Hatchett, M. Tabak, and R. Turner, Phys. Plasmas 10, 1925 (2003).

${ }^{10}$ M. T. Yin and M. L. Cohen, Phys. Rev. Lett. 50, 2006 (1983).

${ }^{11}$ A. M. Liu and M. L. Cohen, Phys. Rev. B 45, 4579 (1992).

${ }^{12}$ R. Biswas, R. M. Martin, R. J. Needs, and O. H. Nielsen, Phys. Rev. B 30, 3210 (1984).

${ }^{13}$ M. van Thiel and F. H. Ree, High Press. Res. 10, 607 (1992).

${ }^{14}$ L. M. Ghiringhelli, J. H. Los, E. J. Meijer, A. Fasolino, and D. Frenkel, Phys. Rev. B 69, 100101 (2004).

${ }^{15}$ S. Scandolo, G. L. Chiarotti, and E. Tosatti, Phys. Rev. B 53, 5051 (1996).

${ }^{16}$ W. B. Hubbard, Science 214, 145 (1981).

${ }^{17}$ F. P. Bundy, W. A. Bassett, M. S. Weathers, R. J. Hemley, H. K. Mao, and A. F. Goncharov, Carbon 34, 141 (1994).

${ }^{18}$ R. Grover, J. Chem. Phys. 71, 3824 (1979).

${ }^{19}$ M. P. Grumbach and R. M. Martin, Phys. Rev. B 54, 15730 (1996).

${ }^{20}$ G. I. Kerley and L. Chabildas, Sandia National Laboratories Report No. SAND2001-2619. See National Technical Information Service Document No. DE2001-787608. Copies may be ordered from the National Technical Information Service, Springfield, VA 22161.

${ }^{21}$ D. A. Young and R. Grover, in Shock Waves in Condensed Matter 1987, in Proceedings of the American Physical Society Topical Conference, edited by S. C. Schmidt and N. C. Holmes (North-Holland, Amsterdam, 1988), pp. 131-134.

${ }^{22}$ T. Sekine, Carbon 31, 227 (1993).

${ }^{23}$ T. Sekine, Appl. Phys. Lett. 74, 350 (1999).

${ }^{24}$ D. K. Bradley, J. H. Eggert, D. G. Hicks, P. M. Celliers, S. J. Moon, R. C. Cauble, and G. W. Collins, Phys. Rev. Lett. 93, 195506 (2004).

${ }^{25}$ M. N. Pavlovskii, Sov. Phys. Solid State 13, 741 (1971).

${ }^{26}$ K. Kondo and T. J. Ahrens, Geophys. Res. Lett. 10, 281 (1983).

${ }^{27}$ X. Wang, S. Scandolo, and R. Car, Phys. Rev. Lett. 95, 185701 (2005).

${ }^{28}$ N. Miyanaga, M. Nakatsuka, H. Azechi, H. Shiraga, T. Kanabe, H. Asahara, H. Daido, H. Fujita, and K. Fujita, in Proceeding of the 18th International Conference on Fusion Energy (IAEA, Sorrento, 2001), IAEACN-77.

${ }^{29}$ S. Skupsky, R. W. Short, T. Kessler, R. S. Craxton, S. Letzring, and J. M. Soures, J. Appl. Phys. 66, 3456 (1989).

${ }^{30}$ R. M. Stevenson, M. J. Norman, T. H. Bett, D. A. Pepler, C. N. Danson, and I. N. Ross, Opt. Lett. 19, 363 (1994).

${ }^{31}$ N. Ozaki, K. A. Tanaka, T. Ono, K. Shigemori, M. Nakai, H. Azechi, T. Yamanaka, K. Wakabayashi, M. Yoshida, H. Nagao, and K. Kondo, Phys. Plasmas 11, 1600 (2004).

${ }^{32}$ K. Nagai, T. Norimatsu, T. Yamanaka, T. Nishibe, N. Ozaki, K. Takamatsu, T. Ono, M. Nakano, and K. A. Tanaka, Jpn. J. Appl. Phys., Part 2 41, L1184 (2002).

${ }^{33}$ A. C. Mitchell and W. J. Nellis, J. Appl. Phys. 52, 3363 (1981).

${ }^{34}$ A. C. Mitchell, W. J. Nellis, J. A. Moriarty, R. A. Heinle, N. C. Holmes, R. E. Tipton, and G. W. Repp, J. Appl. Phys. 69, 2981 (1991).

${ }^{35}$ High-Velocity Impact Phenomena, edited by R. Kinslow (Academic, New York, 1970), p. 294.

${ }^{36}$ W. J. Nellis, A. C. Mitchell, and D. A. Young, J. Appl. Phys. 93, 304 (2003).

${ }^{37}$ H. Nagao, K. Kondo, N. Ozaki, T. Ono, K. Takanatsu, K. Nagai, M. Nakai, K. A. Tanaka, K. Wakabayashi, K. Okada, and M. Yoshida, in Proceeding of the 2nd Asian Conference on High Pressure Research (ACHPR-2) (2004), p. 422.

${ }^{38}$ H. J. McSkimin and P. Andreatch, J. Appl. Phys. 43, 2944 (1972).

${ }^{39}$ F. Occelli, P. Loubeyre, and R. LeToullec, Nat. Mater. 2, 151 (2003).

${ }^{40}$ A. Benuzzi, M. Koenig, B. Faral, J. Krishnan, F. Pisani, D. Batani, S. Bossi, D. Beretta, T. Hall, S. Ellwi, S. Höller, J. Hourubia, and N. Grandjouan, Phys. Plasmas 5, 1 (1998). 